\title{
Sistem Informasi Pengaturan Jadwal Kuliah dengan Metode Timetable
}

\author{
Andrea Stevens Karnyoto * \\ * Program Studi Teknik Informatika, Fakultas Teknik, Universitas Kristen \\ Indonesia Toraja
}

\begin{abstract}
Universitas Kristen Indonesia Toraja memiliki 12 program studi yaitu : Program Studi Pendidikan Bahasa Indonesia, Program Studi Pendidikan Matematika, Program Studi PGSD, Program Studi Pendidikan Bahasa Inggris, Program Studi Pendidikan Fisika, Program Studi Teknologi Pendidikan, Program Studi Manajemen, Program Studi Teologi, Program Studi Teknik Sipil, Program Studi Teknik Mesin, Program Studi Teknik Informatika, Program Studi Teknik Elektro. Pengaturan matakuliah umum (MKU) dilakukan oleh kepengurusan tersendiri. Program studi yang banyak adalah sebuah keunggulan bagi Universitas Kristen Indonesia Toraja tetapi dilain sisi membuat susahnya membuat pengaturan jadwal walaupun ruangan yang terdaftar pada Universitas Kristen Indonesia Toraja untuk kampus 1 sebanyak 32, kampus 2 sebanyak 34, kantor pusat sebanyak 4 dan kampus 3 sebanyak 10. Banyaknya kampus membuat kesulitan tersendiri bagi para dosen untuk mengajar karena jarak antar kampus yang terletak di dua kabupaten. Dengan adanya sistem informasi ini memberikan kemudahan bagi para ketua program studi membuat jadwal kuliah, berdasarkan kasus yang ada pada Program Studi Teknik Informatika Universitas Kristen Indonesia Toraja, untuk membuat jadwal kuliah hanya dibutuhkan waktu 2 jam.
\end{abstract}

Keywords- Jadwal Kuliah, Timetable, Kelas, Ruangan. 


\section{Pendahuluan}

Universitas Kristen Indonesia Toraja memiliki 12 program studi yaitu : Program Studi Pendidikan Bahasa Indonesia, Program Studi Pendidikan Matematika, Program Studi PGSD, Program Studi Pendidikan Bahasa Inggris, Program Studi Pendidikan Fisika, Program Studi Teknologi Pendidikan, Program Studi Manajemen, Program Studi Teologi, Program Studi Teknik Sipil, Program Studi Teknik Mesin, Program Studi Teknik Informatika, Program Studi Teknik Elektro. Pengaturan matakuliah umum (MKU) dilakukan oleh kepengurusan tersendiri.

Program studi yang banyak adalah sebuah keunggulan bagi Universitas Kristen Indonesia Toraja tetapi dilain sisi membuat susahnya membuat pengaturan jadwal walaupun ruangan yang terdaftar pada Universitas Kristen Indonesia Toraja untuk kampus 1 sebanyak 32, kampus 2 sebanyak 34, kantor pusat sebanyak 4 dan kampus 3 sebanyak 10. Banyaknya kampus membuat kesulitan tersendiri bagi para dosen untuk mengajar karena jarak antar kampus yang terletak di dua kabupaten.

Pengembangan sistem informasi pengaturan jadwal kuliah sudah sangat dibutuhkan agar para ketua program studi dan koordinator MKDU mendapatkan solusi terbaik dalam pengaturan jadwal kuliah sehingga dosen, kelas dan ruangan tidak berada pada waktu yang sama atau digunakan bersamaan. Sistem informasi juga sangat bermanfaat bagi para dosen untuk dapat menghitung jumlah matakuliah yang diampunya. Dengan adanya sistem informasi ini membuat jadwal sangat mudah.

\section{Metode Penelitian}

Pengembangan sistem informasi ini menggunakan application based yaitu menggunakan Bahasa pemrograman Delphi 2010 dan untuk mesin databasenya 
menggunakan Microsoft Access. Alasan peneliti membuat menggunakan Delphi dan Microsoft access karena kemudahan dalam instalasi dan menjalankan juga ketangguhan dari perangkat lunak tersebut telah teruji untuk data yang cukup besar.

Karena peneliti juga seorang ketua program studi Teknik Informatika sehingga studi kasus diambil dari Program Studi Teknik Informatika Unversitas Kristen Indonesia.

\section{Metode Penelitian}

Pembuatan sistem informasi ini terdiri dari beberapa menu, seperti yang terlihat gambar 1, menu-menu tersebut digunakan untuk menginput data dan juga untuk melakukan proses.

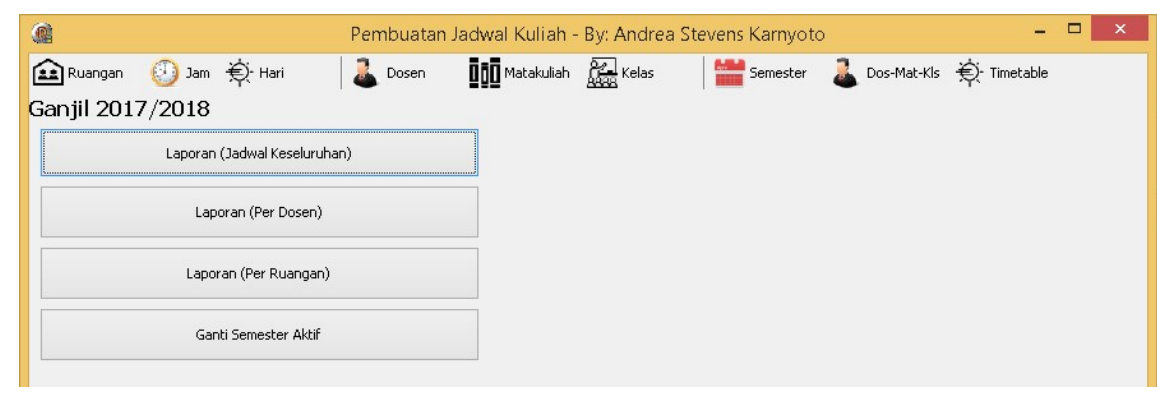

Gambar 1. Menu-menu yang terdapat pada sistem informasi penjadwalan kuliah

Gambar 1 memperlihatkan Sistem informasi ini terdiri dari menu ruangan, jam, hari, dosen, matakuliah, kelas, semester, dos-mat-kls dan yang terakhir adalah timetable. Berikut adalah penjelasan dari menu-menu yang terdapat pada sistem informasi ini. 


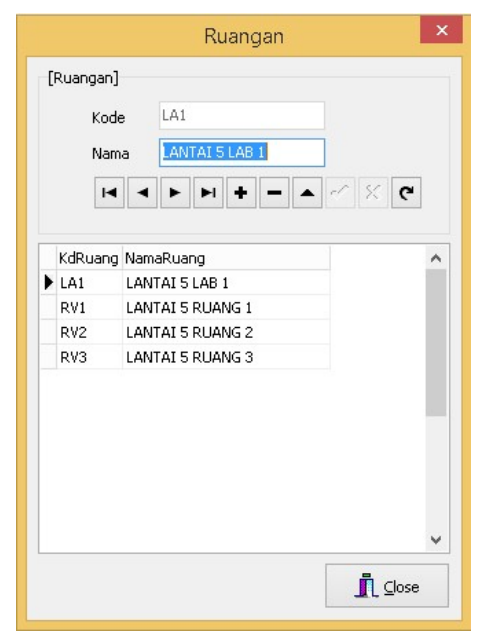

Gambar 2. Form Ruangan

Gambar 2 memperlihatkan form ruangan, yaitu form untuk menambah, menghapus, mengubah ruangan, ruangan yang dimaksud disini adalah ruangan yang terdapat fasilitas belajar mengajar seperti : kursi, meja, papan tulis dan proyektor.

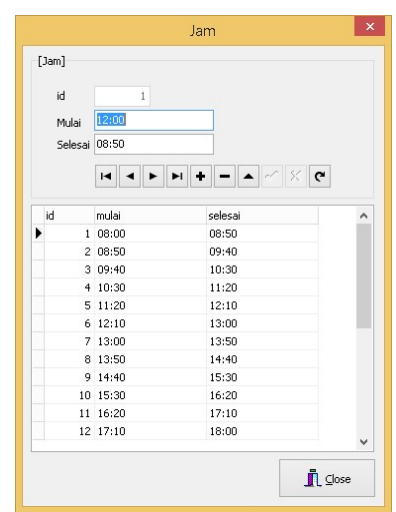

Gambar 3. Form Jam

Gambar 3 menunjukkan gambar form jam, form ini memuat penghapusan, penambahan, dan ubah jam yang akan digunakan. 


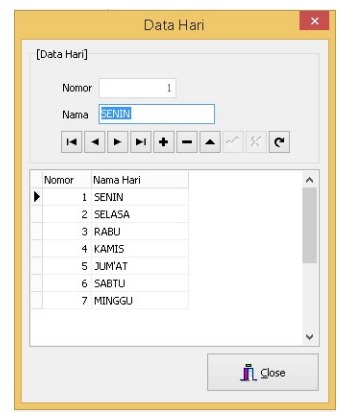

Gambar 4. Form Hari

Form hari pada gambar 4 berisikan data-data nama hari, dalam hal ini peneliti memasukkan seluruh nama hari sehingga terdapat 7 hari dalam seminggu kuliah.

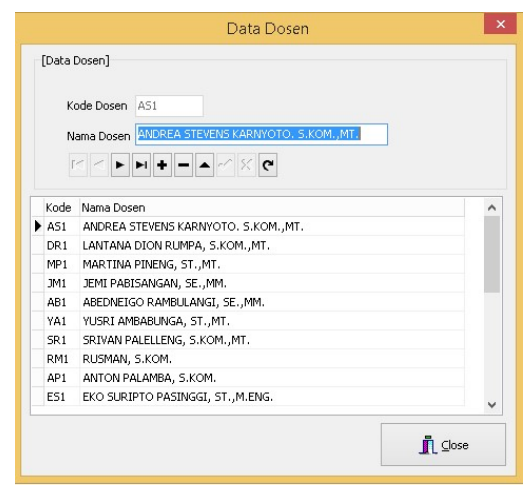

Gambar 5. Form Dosen

Gambar 5 menunjukkan form dosen, data dosen yang dimasukkan disini hanya data kode dosen dan nama dosen karena informasi lain tetang dosen tidak dibutuhkan dalam penyusunan jam mengajar. 


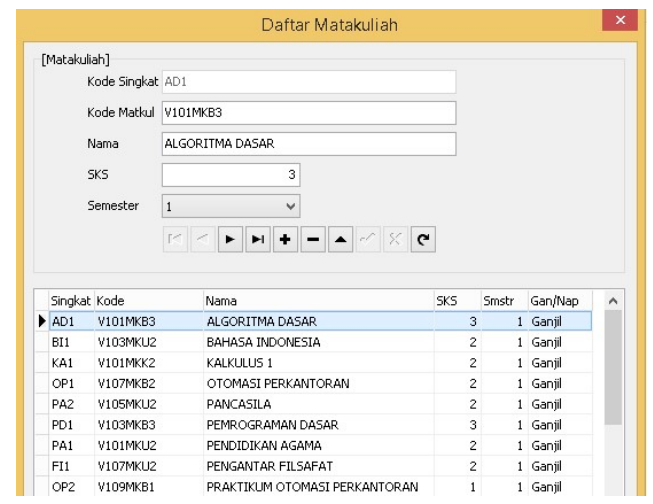

\section{Gambar 6. Form Matakuliah}

Pada gambar 6 memperlihatkan form matakuliah, yang harus dimasukkan dalam form ini adalah: kode singkat, kode matakuliah, nama matakuliah, sks, dan semester. Seluruh informasi tersebut dibutuhkan dalam membuat jadwal kuliah. Kode singkat digunakan untuk mempermudah tampilan dalam grid, kode matakuliah dan nama matakuliah untuk laporan akhir dari matakuliah, sks untuk mendapatkan total jam yang akan berlangsung serta semester digunakan untuk mengetahui apakah kelas tersebut berada pada semester ganjil atau genap.

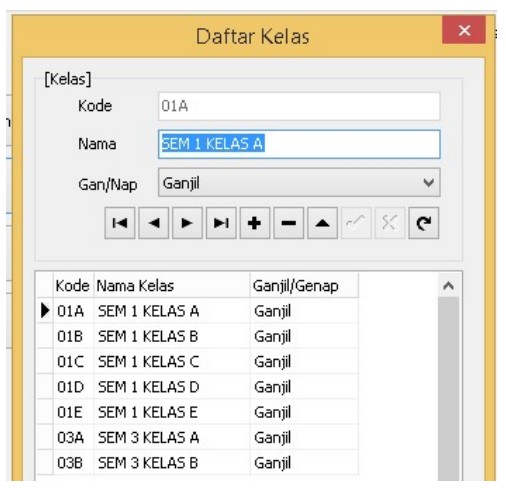

Gambar 7. Form Daftar Kelas

Form kelas pada gambar 7 berisikan nama-nama kelas yang ingin dimasukkan, contohnya pada semester 1 terdapat 5 kelas maka yang ditulis adalah, 01A untuk semester 1 kelas A. begitu seterusnya. 


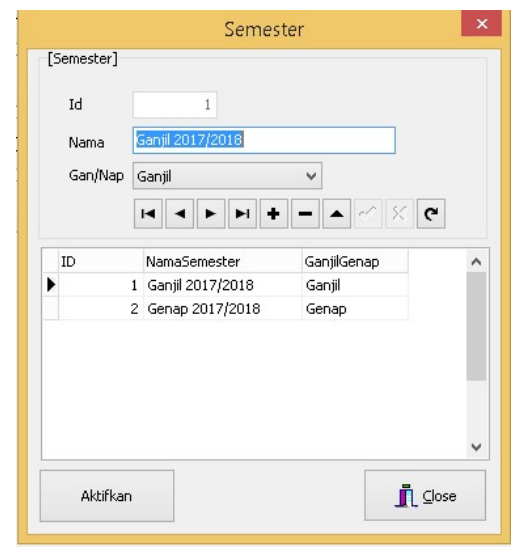

\section{Gambar 8. Form Semester}

Form semester seperti yang terlihat pada gambar 8 adalah form untuk memasukkan semester, sehingga memungkinkan tiap semester memiliki jadwal tersendiri dari hari senin sampai dengan harus sabtu.

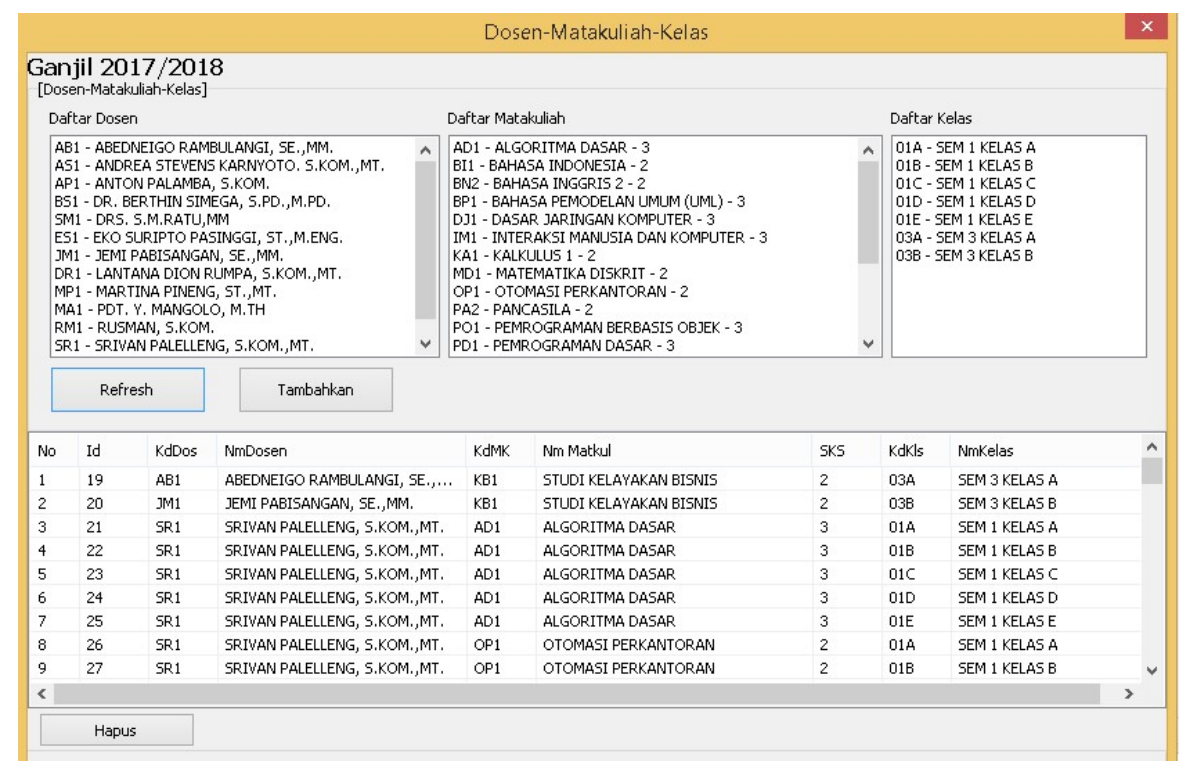

Gambar 9. Tiap dosen dipasangkan dengan matakuliah dan kelas

Untuk memasangkan dosen, matakuliah dan kelas. Pengguna harus menggunakan form dos-mat-kls seperti yang terlihat pada gambar 9. Tiap kelas hanya dapat 
mengambil 1 kali matakuliah, tetapi dosen boleh mengajar matakuliah yang sama dibanyak kelas.

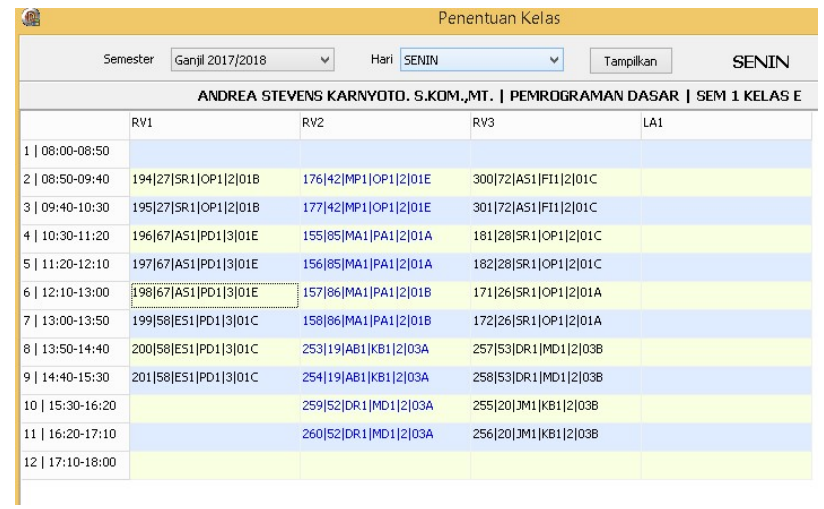

Gambar 10. Form Penentuan Kelas

Pada form penentuan kelas pada gambar 10 memperlihatkan matriks antar jam mengajar dan ruangan, dengan metode timetable ini memberikan kemudahan dalam memasukkan jadwal kuliah.

\section{Kesimpulan}

Dengan adanya sistem informasi ini memberikan kemudahan bagi para ketua program studi membuat jadwal kuliah, berdasarkan kasus yang ada pada Program Studi Teknik Informatika Universitas Kristen Indonesia Toraja, untuk membuat jadwal kuliah hanya dibutuhkan waktu 2 jam.

\section{Daftar Pustaka}

1. Karnyoto, A.S. dan Limpo, M, "Web Tags Formatting with Multilevel Numbering", Information Systems International Conference (ISICO), vol. 1, pp. 25-30, Desember 2013.

2. Karnyoto, A.S., "PERANCANGAN DAN PENGEMBANGAN SISTEM INFORMASI INVENTARISASI MENGGUNAKAN DELPHI" Journal Dynamic Saint, 2014. 